\title{
Title: Incidence of type 1 diabetes in 0-14 year olds in Australia from 2002 to 2017
}

Short running title: Australian incidence of childhood type 1 diabetes

\section{Authors:}

Aveni Haynes MBBChir ${ }^{1}$, Max K. Bulsara $\mathrm{PhD}^{2}$, Phil Bergman $\mathrm{MD}^{3,4}$, Fergus Cameron $\mathrm{MD}^{5,6}$, Jennifer Couper $\mathrm{MD}^{7,8}$, Maria Craig $\mathrm{PhD}^{9,10}$, Karen Demangone GradDip ${ }^{11}$, Stephanie Johnson $\mathrm{PhD}^{12}$, Antony Lafferty MBChB ${ }^{13,14}$, Angela Titmuss $\mathrm{MPH}^{15}$, Elizabeth Davis $\mathrm{PhD}$ ${ }^{1,16}$ On behalf of the APEG/AIHW Diabetes Database Subcommittee

\section{Affiliations:}

${ }^{1}$ Telethon Kids Institute, Perth, Western Australia

${ }^{2}$ Institute for Health Research, University of Notre Dame, Fremantle, Western Australia

${ }^{3}$ Department of Paediatric Endocrinology and Diabetes, Monash Children’s Hospital,

Victoria

${ }^{4}$ Department of Paediatrics, Monash University

This is the author manuscript accepted for publication and has undergone full peer review but has not been through the copyediting, typesetting, pagination and proofreading process, which may lead to differences between this version and the Version of Record. Please cite this article as doi: $10.1111 /$ pedi.13025

This article is protected by copyright. All rights reserved. 
${ }^{5}$ Department of Endocrinology and Diabetes and Centre for Hormone Research, Royal Children's Hospital, Victoria

${ }^{6}$ Murdoch Children’s Research Institute, Victoria

${ }^{7}$ Women's and Children's Hospital, Adelaide, South Australia

${ }^{8}$ Robinson Research Institute, University of Adelaide, South Australia

${ }^{9}$ School of Women's and Children's Health, University of New South Wales

${ }^{10}$ Discipline of Child and Adolescent Health, University of Sydney

${ }^{11}$ Royal Hobart Hospital, Tasmania

${ }^{12}$ Queensland Children's Hospital, Brisbane, Queensland

${ }^{13}$ Department of Paediatrics, Canberra Hospital, Canberra, Australian Capital Territory

${ }^{14}$ ANU Medical School, Canberra, Australian Capital Territory

${ }^{15}$ Royal Darwin Hospital, Northern Territory

${ }^{16}$ Department of Diabetes \& Endocrinology, Perth Children's Hospital, Western Australia

\section{Corresponding Author:}

Dr Aveni Haynes

Children’s Diabetes Centre

Telethon Kids Institute

15 Hospital Avenue

Nedlands

Western Australia

Australia WA 6909 
Tel: +61 864564647

Email: Aveni.Haynes@health.wa.gov.au

Abstract word count: 250 words

Main text word count: 2,722 words

Number of figures: 2

Number of tables: 1 


\section{Objective}

To determine the incidence of childhood onset type 1 diabetes in Australia from 2002 to 2017, and analyse incidence rate trends by calendar year, sex and age at diagnosis.

\section{Research Design and Methods}

Children newly diagnosed with type 1 diabetes aged <15 years between 2002 and 2017 were identified from the National Diabetes Register, estimated as 99\% complete. Data were obtained for diagnosis year, sex, age and residential State/Territory at time of diagnosis. Population estimates by year, sex, single year of age and State/Territory were obtained from the Australian Bureau of Statistics and Poisson regression used to examine incidence and trends by calendar year, sex and age group at diagnosis.

\section{Results}

Between 2002 and 2017, there were 16,783 newly diagnosed cases of type 1 diabetes in children aged $<15$ years (8,684 boys: 8,099 girls), giving a mean incidence of 25.0/100,000 person years (95\%CI:24.6,25.4). A sinusoidal pattern in the incidence rate trend was observed with 5-yearly cycles providing the best model fit. No significant difference was observed in boys compared to girls (IRR 0.98(95\%CI:0.95-1.01)). Compared to 0-4 year olds, the mean incidence was $75 \%$ higher in 5-9 year olds, and $224 \%$ higher in $10-14$ year olds. A decreasing incidence rate trend was observed in 0-4 year old boys and girls.

\section{Conclusions}

This study reports updated incidence and incidence rate trends in children and adolescents diagnosed with type 1 diabetes in Australia. A cyclical pattern in incidence trend persists, with an overall decreasing trend observed only in the youngest age group. 


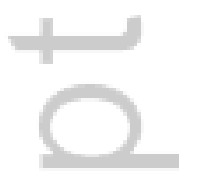




\section{Introduction}

Ongoing monitoring of the incidence of childhood type 1 diabetes is essential for informing health service planning and health care delivery to children and their families affected by this chronic lifelong condition and its significant associated morbidities. In addition, changes in the epidemiology of childhood type 1 diabetes provide clues on environmental factors associated with the disease, whose cause(s) remains unknown (1). For example, epidemiological studies have provided evidence for wide geographic variation in the global incidence of childhood type 1 diabetes, including in neighbouring countries such as Finland and Estonia, as well as differing temporal trends in different populations and subgroups, such as migrants and children aged less than 5 years (1).

A study of 26 centres in 22 countries across Europe from 1989 to 2013 reported significant increases in incidence in all but two centres, with a pooled estimated average increase in incidence of 3.4\% per year over this time period (2). Variability in the rate of increase was observed between centres in this study, with the highest rate of increase reported as $6.6 \%$ per year in Poland, and a reduced rate of increase in the most recent years observed in highincidence populations such as Finland and Sweden (2). In the US, the SEARCH for diabetes in youth study reported that the incidence of type 1 diabetes in youth aged $<19$ years increased by an average of 1.8\% a year between 2002 and 2012, with a higher rate of increase observed in Hispanic compared to non-Hispanic whites (3). 
In Australia, the mean annual incidence of type 1 diabetes in 0 to 14 year olds was last reported as being 23.6 per 100,000 person years from 2000 to 2011(4) with an annual increase in incidence only observed in the oldest age group of 10-14 year olds. Of interest, this study also reported a non-linear, sinusoidal pattern in the incidence rate trend of childhood type 1 diabetes over this period, with evidence for 5-yearly peaks and troughs in the incidence for both sexes, and all age groups (4). A 4-year cyclical pattern in the temporal trend of incidence was reported recently in 4 of the 26 centres analysed across Europe (2). Analysis of the incidence of childhood type 1 diabetes in Western Australia up to 2016, which accounts for approximately ten percent of the total Australian population, reported a possible plateauing of the incidence of type 1 diabetes in 0 to 14 year olds resident in this Australian State, following a peak in incidence observed in 2003 (5). Therefore, this study aimed to determine the incidence and incidence rate trends of type 1 diabetes in children aged 0 to14 years Australia-wide using all available data from 2002 to 2017, and to examine the temporal trends for non-linear patterns, including any evidence of a plateau.

\section{Methods}

The study population was all cases of childhood type 1 diabetes diagnosed in Australia between $1^{\text {st }}$ January 2002 and $31^{\text {st }}$ December 2017. Cases were defined as children newly diagnosed with type 1 diabetes during the study period, aged less than 15 years, and resident in Australia at the time of diagnosis. 
Cases were identified from the National Diabetes Register (NDR) which records all new cases of insulin-treated diabetes mellitus in Australia where insulin use commenced on or after 1 January 1999, and is maintained by the Australian Institute of Health and Welfare. For 0 to 14 year olds, data in the NDR are derived annually from two primary data sources: the State and Territory Australasian Paediatric Endocrinology (APEG) diabetes databases and the National Diabetes Services Scheme (NDSS) database maintained by Diabetes Australia, which results in an estimated case ascertainment of $>99 \%$ (6). The diagnosis of type 1 diabetes in the APEG registries is based on the ISPAD guidelines (7) and diabetes autoantibody testing is routinely performed.

Data on all eligible cases of type 1 diabetes were extracted from the NDR by managers of the register at the Australian Institute of Health and Welfare, and de-identified data provided for analysis on diabetes type, date of diagnosis, sex, age at diagnosis and Australian State/Territory of residence. Due to Australian data privacy restrictions for small cell counts, case numbers were not available by single year of age and provided in 5-year age groups for age at diagnosis (0-4 years, 5-9 years and 10-14 years). Population estimates by calendar year, sex, single year of age and State/Territory of Australia published by the Australian Bureau of Statistics were used as the denominator data (8). Annual direct age-standardised incidence rates using the Australian standard population (8), as well as gender- and age-specific incidence rates were calculated, and Poisson regression used to analyse incidence rates by calendar year, sex and age at diagnosis. As previously described (4), to analyse the incidence for non-linear variation, sine and cosine functions were applied to Poisson regression models for 3-, 4-, 5-, 6-, and 7- 
year cycles and the Akaike Information Criterion (AIC) used to assess goodness-of-fit (9; 10). Being an exploratory study, analyses did not adjust for multiple testing and the results must therefore, be interpreted accordingly.

This study received approval from the Child and Adolescent Health Service Ethics Committee and the Western Australia Department of Health Human Research Ethics Committee.

\section{Results}

Incidence

Between 2002 and 2017, there were 16,783 (8,684 boys: 8,099 girls) newly diagnosed cases of type 1 diabetes in 0 to 14 year olds identified from the NDR (Table 1), giving an overall mean annual incidence over the study period of 25.0 per 100,000 person years (95\%CI: 24.6, 25.4). No significant difference was observed in the mean incidence of boys compared to girls (IRR 0.98 (95\%CI: 0.95, 1.01)) and for both boys and girls, the lowest mean incidence was observed in 0 to 4 year olds, and highest in 10 to 14 year olds (Table 1 ). With boys and girls combined, the mean incidence was 75\% higher in 5 to 9 year olds (Incidence rate ratio (IRR) 1.75 (95\%CI: 1.76, 1.82) and 224\% higher in 10-14 year olds (IRR 2.24 (95\%CI: 2.15, 2.33).

\section{Incidence rate trends}

With both sexes and all age groups combined, there was an overall linear decreasing trend with an average annual decrease in incidence of 0.9\% per year (IRR 0.991 (9\%CI: 0.987 - 0.994), $p<0.001)$. When analysed by sex, a similar linear decreasing trend was observed in both boys 
and girls. However, when stratified by sex and age group at diagnosis, a statistically significant decreasing trend in incidence was only observed in 0 to 4 year old boys (-2.5\% per year (IRR 0.975 (95\%CI: 0.966, 0.985)) and girls (-1.4\% per year (IRR 0.986 (95\%CI: 0.976, 0.997)) (Table 1).

\section{5-yearly cyclical trend}

On analysis of the temporal incidence rate trend for non-linear variation, a sinusoidal pattern was observed overall (Figure 1), in both boys and girls, and in all age groups (Figure 2). A sinusoidal pattern with a 5-yearly interval between peaks and troughs provided the model of best fit (AIC 10.78) and showed an overall average annual decreasing trend of $0.8 \%$ (IRR 0.992 (95\%CI: 0.989, 0.995), $\mathrm{p}<0.001$ ). When analysed by sex, a decreasing trend was observed in both boys (IRR=0.999 (95\%CI: 0.985, 0.994) and girls (IRR 0.994 (95\%CI: 0.989, 0.999). However, when stratified by sex and age group at diagnosis, a statistically significant decreasing trend in incidence was only observed in 0 to 4 year old boys (-2.9\% per year (IRR 0.981(95\%CI: $0.973,0.988)$ ) and 0 to 4 year old girls $(-1.3 \%$ per year (IRR 0.997 (95\%CI: $0.992,1.002))$.

\section{Discussion}

This national, population-based study reports ongoing non-linear variation in the incidence of childhood type 1 diabetes in Australia from 2002 to 2017, and a decreasing trend in incidence observed in the youngest age group of 0 to 4 year olds. Consistent with previous reports from Australia (4), this study found evidence for a sinusoidal pattern in the incidence of childhood 
type 1 diabetes in boys and girls of all age groups, with a periodicity of 5-years providing the best model fit. Evidence for similar periodicity to peaks in incidence of the disease have also been observed in Poland (11), North East England (12), and other European centres (2). Such observations of cyclical patterns with regular peaks and troughs in the incidence of type 1 diabetes are intriguing, and raise the question of what environmental factors display similar trends that could be playing a role in the aetiology or clinical onset of childhood type 1 diabetes (4). Why such temporal patterns in the incidence of childhood type 1 diabetes are evident in some but not all populations suggests that the interaction between genetic predisposition and environmental agents varies across different populations (2). However, differences in registry definitions and diagnostic criteria for T1D, such as islet autoantibody testing at diagnosis for classification not being a mandatory requirement in EURODIAB, may also contribute to discrepancies between populations (2). Despite there being no explanation for the cyclical variation in incidence as yet, such non-linear trends in the incidence of childhood type 1 diabetes are still an important consideration for health service planning and delivery, and the appropriateness of assuming linear trends in these populations when undertaking data modelling for predictive purposes.

The wide geographical variation in mean incidence of childhood type 1 diabetes is a wellestablished characteristic of its epidemiology, and although not yet fully understood, is thought to reflect geographical differences in underlying genetic susceptibility and environmental risk and/or protective factors and their interaction (13). An overall increasing trend in incidence of childhood type 1 diabetes continues to be observed in most populations with data available 
from longitudinal prospective diabetes registers established several decades ago. A possible levelling off in incidence has been reported in several European populations (14-16). However, a recent analysis of 26 European centres, observed an ongoing increase in incidence in these centres albeit at a lower rate than the overall pooled estimate of an average annual increase of $3.4 \%$ a year over the past 25 years (2).

In contrast, this study reports an overall $<1 \%$ average annual decreasing trend in the incidence of type 1 diabetes in 0 to 14 year olds in Australia between 2002 and 2017, with 5-yearly cyclical peaks and troughs. Of particular interest, is the finding that the overall decreasing trend is accounted for by a decreasing trend in incidence in the youngest age group of 0 to 4 year old boys and girls. This is similar to findings from the SEARCH study which reported an unadjusted average 1.2\% annual decreasing trend in incidence of type 1 diabetes in 0 to 4 year olds which became less statistically significant after adjusting for sex and ethnicity/race (3).

This decreasing trend observed in this study is not explained by changes in ascertainment of cases over the study period. In Australia, children diagnosed with diabetes are admitted to hospital at the time of diagnosis for investigation and initiation of insulin therapy and managed by paediatric endocrinologists or paediatricians, making it highly unlikely that new onset cases in this youngest age group would be missed. Confirming this, the case ascertainment for all age groups was found to be $>99 \%$ complete throughout the study period (Personal communication Pearl Ng, NDR data manager at Australian Institute of Health and Welfare, September 2019). Another possible explanation for the decreasing trend in paediatric type 1 
diabetes could be the increased awareness of, and access to efficient and affordable testing for monogenic diabetes in Australia over the past decades. However, the prevalence of these disorders has not increased over this period, and the peak age for diagnosis is around puberty, not specifically under 5 year olds.

Notably, the linear decreasing trend observed in this study appears to be consistent over the entire study period, albeit with peaks and troughs in incidence occurring 5-yearly. Joinpoint regression analysis did not show a significant change in the slope of the linear incidence rate temporal trend between 2002 and 2017 (data not shown). This is in contrast to an Australian study which reported a 15\% reduction in the national incidence of type 1 diabetes in children aged $0-4$ years in 2008, following the introduction of the rotavirus vaccination into the routine Australian national immunisation program for infants aged 6 weeks and older in 2007 (17). This may be explained by the different methods used in this study, which did not apply an intermittent time-series approach, rather Poisson regression with sine and cosine functions to take into account cyclical variation in the incidence rate trends, which have previously been published (4). In addition, this study ascertained cases of type 1 diabetes from the National Diabetes Register which sources cases from both the National Diabetes Subsidy Scheme (NDSS) and national Australasian Paediatric Endocrinology Group (APEG) registers. As acknowledged by the authors of the study reporting the $15 \%$ decrease in type 1 diabetes incidence in relation to introduction of the rotavirus immunisation in Australia, the selection of set change points is a challenge when analysing data with non-linear patterns (17); the $15 \%$ decrease in incidence reported in 2008 coincided with a downward trend in incidence as 
illustrated in Figure 1. It is difficult to explain a 15\% decrease in type 1 diabetes incidence in the first year following the introduction of rotavirus vaccination, when only those under 1 years old would have received the vaccination, and no subsequent decreasing trend being observed following this stepwise decrease (17). Rather an ongoing decreasing trend would be expected, as the number of children vaccinated against rotavirus increases in the population and vaccinated children grow older, towards the peak age of type 1 diabetes onset. However, the potential role of rotavirus vaccination on the decreasing trend of type 1 diabetes incidence has also been observed in a large study in the United States (18), but not in Finland (19), and remains an important association requiring further research. For example, in Australia the national immunisation program recommends the administration of either Rotarix ${ }^{\circledR}$ at 2 and 4 months, or RotaTeq ${ }^{\circledR}$ at 2, 4 and 6 months of age (20). Although the national coverage rate for rotavirus vaccination uptake has continued to remain high since its introduction in 2007 (21), the type of vaccine routinely administered varies between different States and Territories (22). Future research needs to analyse differences in association between type 1 diabetes incidence and rotavirus vaccine type, as RotaTeq ${ }^{\circledR}$ which is a pentavalent human-bovine reassortant vaccine may have greater plausible biological mechanims relevant to type 1 diabetes aetiology, compared to the human monovalent Rotarix ${ }^{\circledR}$ vaccine (23).

The strengths of the study are its use of population-based data with ascertainment levels of consistent $>99 \%$ completeness (6) and classification of type 1 diabetes by paediatric endocrinologists and paediatricians using current diagnostic and diabetes classification criteria (7). In addition, the decreasing trend observed in this study takes into account the non-linear 
pattern in incidence of type 1 diabetes. A limitation of this study was the inability to account for changes in the ethnic/race composition of the Australian population at risk of type 1 diabetes, which has changed over the past decade (24). Data from the 2016 Australian census showed that $26 \%$ of the Australian population were born overseas, and that $18 \%$ of these had arrived since 2012. Of note, the proportion of overseas born migrants from China and India increased between the 2011 and 2016 censuses, reflecting the changing demographic characteristics of the Australian population (24). Although country of birth and ancestry are collected during the 50-yearly Australian National census, data on this are not publicly available by age group or sex. So whether or not the decreasing trend of type 1 diabetes incidence in younger children could be accounted for by an increasing number of nonCaucasoid families migrating to Australia with first generation offspring, who have a reduced genetic risk of the disease, is not known.

This study provides updated data on the incidence and incidence rate trends of type 1 diabetes in Australian children and adolescents aged less than 15 years between 2002 and 2017. The findings of a decreasing incidence rate trend in the youngest age group of 0 to 4 year old boys and girls, is of particular interest, as is the persistent non-linear cyclical pattern in incidence. These observations illustrate the need for ongoing monitoring of the incidence of type 1 diabetes, a disease whose cause remains unknown, and whose epidemiology is dynamic and variable by population at risk and geographical location $(2,25)$. 
Acknowledgements: The authors would like to acknowledge James Pearce and Pearl Ng at the Australian Institute for Health and Welfare (NDR, AIHW, Canberra) for their support and assistance with obtaining the relevant approvals and providing the NDR data extract required for this study to be undertaken; Australasian Paediatric Endocrinology Group (APEG) and its members for their contribution in collecting data which is provided to the AIHW NDR from paediatric diabetes registers.

\section{Author Contributions}

A.H was responsible for the study design, data management and analysis, interpretation of statistical findings, literature review and writing of the manuscript. M.K.B was responsible for analysis of non-linear patterns and cyclical trend analysis, interpretation and reviewed the manuscript. P.B., F.C, J.C, M.C., K.D., S.J., A.L., A.T. and E.D contributed to study development, interpretation of findings, discussion and reviewed the manuscript.

Study guarantor: Elizabeth Davis is the guarantor for this study, and takes full responsibility for the research presented for publication.

\section{Conflicts of Interest}

A. Haynes: None declared

M.K. Bulsara: None declared

P. Bergman: None declared 
F. Cameron: None declared

J. Couper: None declared

M. Craig: None declared

K. Demangone: None declared

S. Johnson: None declared

A. Lafferty: None declared

A. Titmuss: None declared

E.A. Davis: None declared 


\section{References}

1. Atkinson MA, Eisenbarth GS, Michels AW: Type 1 diabetes. Lancet 2014;383(9911):6982

2. Patterson CC, Harjutsalo V, Rosenbauer J, et al. Trends and cyclical variation in the incidence of childhood type 1 diabetes in 26 European centres in the 25 year period 19892013: a multicentre prospective registration study. Diabetologia 2019 [Epub 2018 Nov 28];62(3):408-417.

3. Mayer-Davis EJ, Lawrence JM, Dabelea D, et al.: Incidence Trends of Type 1 and Type 2 Diabetes among Youths, 2002-2012. NEJM 2017;376(15):1419-1429.

4. Haynes A, Bulsara M, Bower C, Jones T, Davis E: Regular peaks and troughs in the Australian incidence of childhood type 1 diabetes mellitus (2000-2011). Diabetologia 2015;58(11):2513-2516.

5. Haynes A, Bulsara MK, Jones TW, Davis EA: Incidence of childhood onset type 1 diabetes in Western Australia from 1985 to 2016: Evidence for a plateau. Pediatr Diabetes 2018(4);19:690-692.

6. Australian Institute for Health and Welfare: The National (insulin-treated) Diabetes Register 2017; Quality Statement. Available at https://meteor.aihw.gov.au/content/index.phtml/itemId/714433 Accessed Nov 2019. 7. Mayer-Davis EJ, Kahkoska AR, Jefferies C, et al.: ISPAD Clinical Practice Consensus Guidelines 2018: Definition, epidemiology, and classification of diabetes in children and adolescents. Pediatr Diabetes 2018;19:7-19.

8. Australian Bureau of Statistics: 31010 Australian Demographic Statistics Table 59. Estimated Resident Population By Single Year Of Age, Australia. Available at https://www.abs.gov.au/AUSSTATS/abs@.nsf/DetailsPage/3101.0Dec\%202018?OpenDocu ment Accessed Sep 2019.

9. Stolwijk AM, Straatman H, Zielhuis GA: Studying seasonality using sine and cosine functions in regression analysis. J Epidemiol Community Health 1999;53(4):235-238. 
10. Christiansen CF, Pedersen L, Sørensen HT, Rothman KJ: Methods to assess seasonal effects in epidemiological studies of infectious diseases-exemplified by application to the occurrence of meningococcal disease. Clin Microbiol Infect 2012;18(10):963-969.

11. Chobot A, Polanska J, Brandt A, et al.: Updated 24-year trend of Type 1 diabetes incidence in children in Poland reveals a sinusoidal pattern and sustained increase. Diabet Med 2017; 34(9)1252-1258.

12. McNally RJQ, Court S, James PW, Pollock R, Blakey K: Cyclical Variation in Type 1 Childhood Diabetes. Epidemiology 2010;21(6):914.

13. Rewers M, Ludvigsson J: Environmental risk factors for type 1 diabetes. Lancet 2016;387(10035):2340-2348.

14. Skrivarhaug T, Stene L, Drivvoll A, Strøm H, Joner G: Incidence of type 1 diabetes in Norway among children aged 0-14 years between 1989 and 2012: has the incidence stopped rising? Results from the Norwegian Childhood Diabetes Registry. Diabetologia 2014;57(1):57-62.

15. Harjutsalo V, Sund R, Knip M, Groop P: Incidence of type 1 diabetes in Finland. JAMA 2013;310(4):427-428.

16. Berhan Y, Waernbaum I, Lind T, Möllsten A, Dahlquist G: Thirty Years of Prospective Nationwide Incidence of Childhood Type 1 Diabetes: The Accelerating Increase by Time Tends to Level Off in Sweden. Diabetes 2011;60(2):577-581.

17. Perrett KP, Jachno K, Nolan TM, Harrison LC: Association of Rotavirus Vaccination With the Incidence of Type 1 Diabetes in ChildrenAssociation of Rotavirus Vaccination With the Incidence of Type 1 Diabetes in Children. JAMA Pediatr. 2019;173(3):280-282.

18. Rogers MAM, Basu T, Kim C: Lower Incidence Rate of Type 1 Diabetes after Receipt of the Rotavirus Vaccine in the United States, 2001-2017. Sci Rep. 2019;9(1):7727. 19. Vaarala O, Jokinen J, Lahdenkari M, Leino T: Rotavirus Vaccination and the Risk of Celiac Disease or Type 1 Diabetes in Finnish Children at Early Life. Pediatr Infect Dis J. 2017;36(7):674-675.

20. Australian Government Department of Health: National Immunisation Program Childhood Vaccination Schedule. Available at https://www.health.gov.au/health- 
topics/immunisation/immunisation-throughout-life/national-immunisation-programschedule\#national-immunisation-program-schedule-from-1-april-2019 Accessed Nov 2019. 21. Hull BP, Hendry AJ, Dey A, Beard FH, Brotherton JM, PB M: Annual Immunisation Coverage Report 2016. Available at http://www.ncirs.org.au/sites/default/files/201811/NCIRS-Annual-Immunisation-Coverage-Report-2016.pdf Accessed Nov 2019.

22. Roczo-Farkas S, Kirkwood CD, Cowley D, et al.: The Impact of Rotavirus Vaccines on Genotype Diversity: A Comprehensive Analysis of 2 Decades of Australian Surveillance Data. J Infect Dis. 2018;218(4):546-554.

23. Harrison LC, Perrett KP, Jachno K, Nolan TM, Honeyman MC: Does rotavirus turn on type 1 diabetes? PLoS pathogens 2019;15: e1007965-e1007965

24. Australian Bureau of Statistics: Cultural Diversity in Australia, 2016. Available at https://www.abs.gov.au/ausstats/abs@.nsf/Lookup/by\%20Subject/2071.0 2016 Main\%20Fe atures Cultural\%20Diversity\%20Article 60 Accessed Nov 2019.

25. Knip M: Descriptive epidemiology of type 1 diabetes - is it still in? Diabetologia 2012;55(5):1227-1230. 
Table 1: Number of newly diagnosed cases, total person years at risk, mean incidence and average annual change in incidence rate of type 1 diabetes in 0 to 14 year olds in Australia by sex and age at diagnosis from 2002 to 2017

\begin{tabular}{|c|c|c|c|c|}
\hline $\begin{array}{c}\text { Sex and } \\
\text { age group at } \\
\text { diagnosis } \\
\end{array}$ & $\begin{array}{l}\text { Cases } \\
(\mathbf{N})\end{array}$ & $\begin{array}{l}\text { Total } \\
\text { person } \\
\text { years }\end{array}$ & $\begin{array}{c}\text { Mean annual } \\
\text { incidence per } 100,000 \\
(95 \% \mathrm{CI}) \\
\end{array}$ & $\begin{array}{l}\text { Average annual change in } \\
\text { incidence } \operatorname{IRR}(95 \% \mathrm{CI})\end{array}$ \\
\hline \multicolumn{5}{|l|}{ Boys } \\
\hline $0-4$ years & 1,785 & $11,306,204$ & $15.8(15.1,16.5)$ & $0.975(0.966,0.985)^{*}$ \\
\hline 5-9 years & 2,814 & $11,196,304$ & $25.1(24.2,26.1)$ & $0.994(0.986,1.002)$ \\
\hline 10-14 years & 3,917 & $11,131,154$ & $35.2(34.1,36.3)$ & $0.996(0.989,1.003)$ \\
\hline $0-14$ years & 8,516 & $33,633,662$ & $25.3(24.8,25.9)$ & $0.991(0.987,0.996)^{*}$ \\
\hline \multicolumn{5}{|l|}{ Girls } \\
\hline $0-4$ years & 1,547 & $10,721,671$ & $14.4(13.7,15.2)$ & $0.986(0.976,0.997)^{\dagger}$ \\
\hline 5-9 years & 2,956 & $10,624,169$ & $27.8(26.8,28.8)$ & $0.996(0.988,1.003)$ \\
\hline 10-14 years & 3,444 & $10,560,424$ & $32.6(31.5,33.7)$ & $0.997(0.990,1.005)$ \\
\hline $0-14$ years & 7,947 & $31,906,264$ & $23.0(22.4,23.7)$ & $0.994(0.990,0.999)^{\ddagger}$ \\
\hline \multicolumn{5}{|l|}{ Boys \& girls } \\
\hline $0-4$ years & 3,332 & $22,027,875$ & $15.1(14.6,15.7)$ & $0.980(0.973,0.988)^{*}$ \\
\hline 5-9 years & 5,770 & $21,820,473$ & $26.4(25.8,27.1)$ & $0.995(0.989,1.000)$ \\
\hline 10-14 years & 7,361 & 22,039,639 & $33.4(32.6,34.2)$ & $0.997(0.992,1.002)$ \\
\hline 0 -14 years & 16,463 & $65,887,987$ & $25.0(24.6,25.4)$ & $0.991(0.987-0.994) *$ \\
\hline
\end{tabular}


Figure 1: Incidence of childhood type 1 diabetes among children aged 0 to 14 years in Australia (2002-2017); Solid line with dots = Observed incidence, dotted line $=$ Predicted incidence using 5-year sinusoidal Poisson regression model, dashed line $=$ Linear temporal incidence rate trend 
Figure 2: Incidence of type 1 diabetes among children aged 0 to 14 years in Australia by sex, age group at diagnosis and calendar year from 2002 to 2017; Dotted line $=0-4$ years, Dashed line $=5-9$ years, Solid line $=10-14$ years 


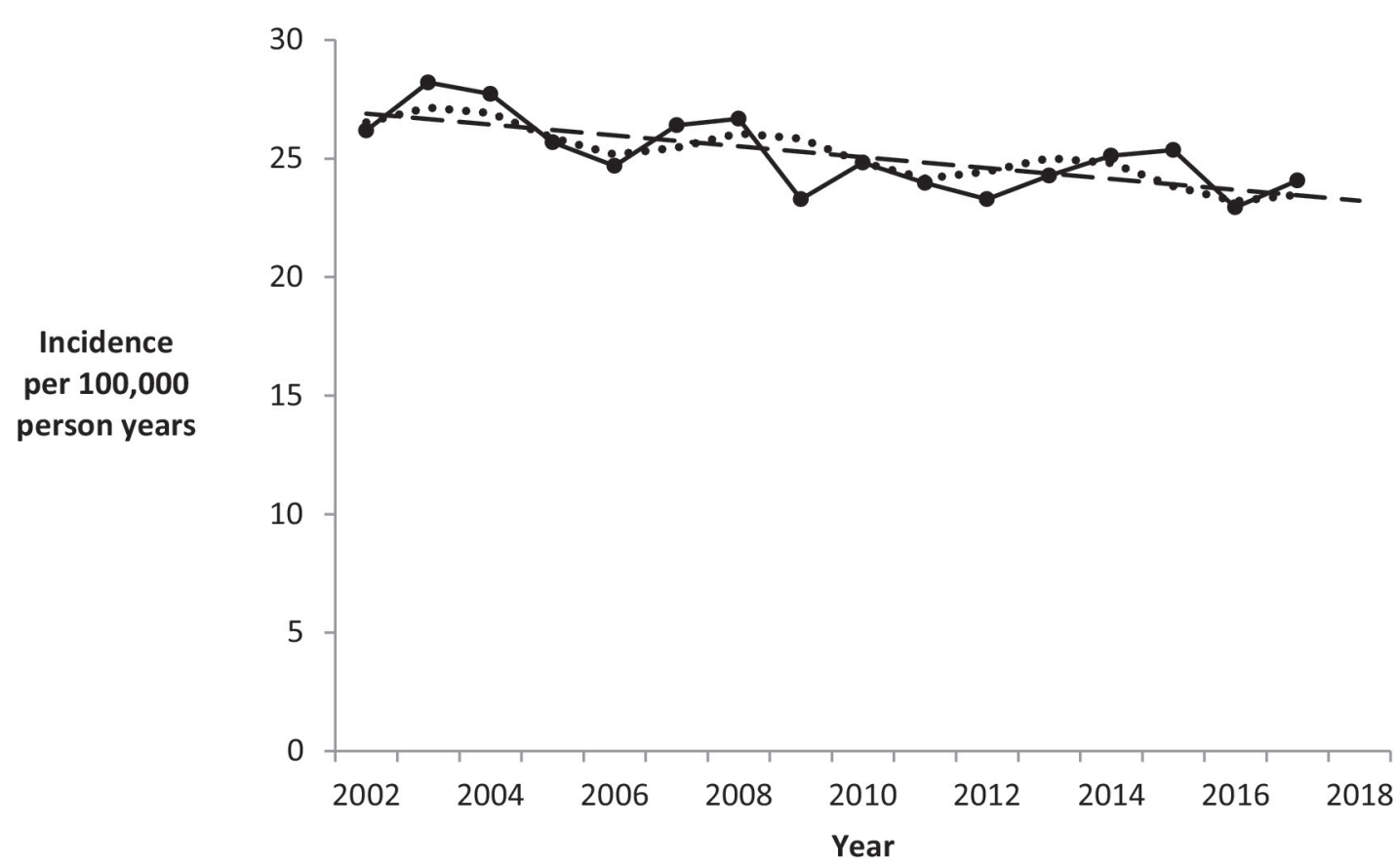

pedi_13025_haynes_nationalinc2002_2017_figure1_r1 figure.eps

This article is protected by copyright. All rights reserved. 


\section{Boys}

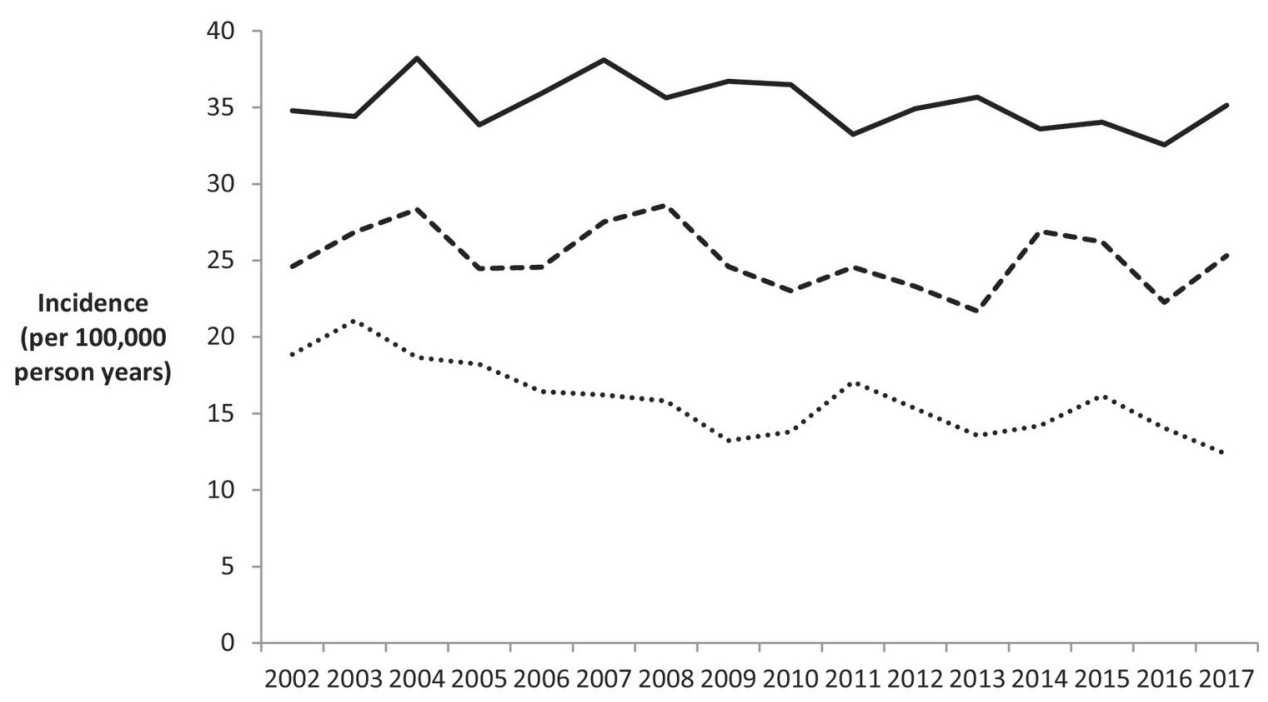

Girls

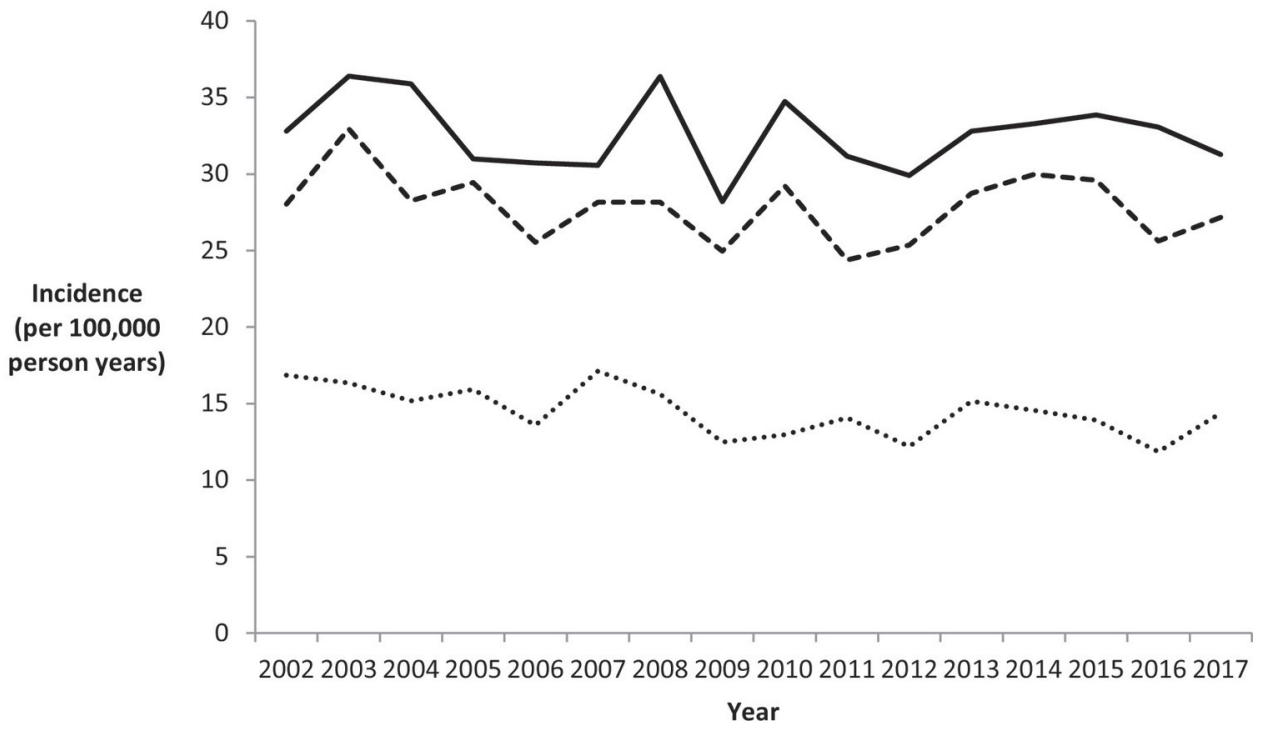

pedi_13025_haynes_nationalinc2002_2017_figure2_r1.eps

This article is protected by copyright. All rights reserved. 


\section{University Library}

\section{- M M N E R VA A gateway to Melbourne's research publications}

Minerva Access is the Institutional Repository of The University of Melbourne

\section{Author/s:}

Haynes, A;Bulsara, MK;Bergman, P;Cameron, F;Couper, J;Craig, ME;Demangone,

K;Johnson, S;Lafferty, A;Titmuss, A;Davis, EA

Title:

Incidence of type 1 diabetes in 0 to 14 year olds in Australia from 2002 to 2017

\section{Date:}

2020-05-31

\section{Citation:}

Haynes, A., Bulsara, M. K., Bergman, P., Cameron, F., Couper, J., Craig, M. E., Demangone, K., Johnson, S., Lafferty, A., Titmuss, A. \& Davis, E. A. (2020). Incidence of type 1 diabetes in 0 to 14 year olds in Australia from 2002 to 2017. PEDIATRIC DIABETES, 21 (5), pp.707-712. https://doi.org/10.1111/pedi.13025.

Persistent Link:

http://hdl.handle.net/11343/275795 